\title{
ALLAH PENCIPTA HADIR DI SINI BERSAMA CIPTAANNYA Refleksi Ekologis Kontekstual
}

\author{
Largus Nadeak*
}

\begin{abstract}
Abstrak
“Berpikir global dan bertindak lokal!" merupakan seruan ekologis yang perlu ditidaklanjuti dan direalisasikan. Dalam hidup nyata setiap hari di tempatnya dan di waktu sekarang umat Kristen bersama dengan masyarakat dipanggil berpartisipasi memelihara karya Allah yang nyata di bumi dan isinya. Kekayaan dan keindahan bumi sangat terbuka untuk kegiatan bisnis pariwisata. Badan Pelaksanaan Otorita Danau Toba (BPODT) sedang merancang Danau Toba sebagai belahan bumi yang indah menjadi tujuan pariwisata. Masyarakat Batak-Toba yang mayoritas tinggal di sekitar Danau Toba memiliki budaya dan tradisi religius. Suku Batak-Toba memiliki kisah penciptaan yang sangat khas, dan nilai yang ada dalam kisah penciptaan tersebut tersebar di tata budaya dan tindakan religi yang bermuatan kelestarian kekayaan alam. Masyarakat sekitar Danau Toba dipanggil agar giat berperan memelihara lingkungan serta melestarikan budaya dan tradisi religi yang sungguh bermakna bagi banyak orang. Kegiatan pengembangan ekonomi pariwisata seharusnya menghargai nilai budaya dan kekayaan religi yang ada, serta mendukung masyarakat setempat dan orang yang berkunjung untuk mengalami dan mengungkapkan bahwa Allah hadir sini bersama ciptaan-Nya.
\end{abstract}

Kata-kata kunci: Allah, bumi, beriman, membudaya, pariwisata, ekologi, Batak-Toba.

\section{Pendahuluan}

"Sesungguhnya Tuhan ada di tempat ini..." Demikian ungkapan Yakub ketika mengalami kehadiran Allah di tempatnya (Kej 28, 16). Kehadiran Allah Pencipta dan tindakan penciptaan-Nya dikisahkan dalam Kitab Kejadian (Perjanjian Lama) dalam dua versi ${ }^{1}$. Perbedaan versi ini muncul karena pelukisan penciptaan dipengaruhi oleh konteks

${ }^{1}$ Kitab Kejadian memiliki 2 versi kisah penciptaan bumi dan isinya khususnya penciptaan manusia, yaitu Kejadian 1, 26-27 bertradisi imamat (priester), dan Kejadian 2, 7 bertradisi yahwista. 
penulisannya. Walaupun versinya berbeda (dengan versi yang khas), isinya sama yaitu Allah menciptakan segala sesuatu baik adanya.

Kisah penciptaan juga ada di beberapa daerah, salah satunya di daerah Batak-Toba, di Gunung Pusuk Buhit di tepi Danau Toba. Kisah penciptaan dengan versi berbeda sungguh berharga karena membuka pemahaman kaya dan bermakna bahwa Allah Pencipta hadir "di sini", hadir di mana-mana bersama ciptaan-Nya. Kisah penciptaan dengan variasi versi membungkus kekayaan berharga, berisi kekayaan rohani dan budaya tradisional yang mengajak orang untuk menghargai bumi dan semua isinya.

\section{Kenal Tempat Kita}

Ketika Yakub bangun dari tidurnya, berkatalah ia, "Sesungguhnya Tuhan ada di tempat ini, dan aku tidak mengetahuinya." Ia takut dan berkata, "Alangkah dasyatnya tempat ini. Ini tidak lain dari rumah Allah, ini pintu gerbang surga." (Kej 28, 16-17)

Yakub mengalami Allah hadir di tempatnya. Allah hadir di sini. Dia mengalami berada di rumah Allah. "What is described here is a phenomenon of religion as a whole; it occurs in many stages in the history of mankind throughout the world."2 Kisah iman ini berpesan bahwa Allah bisa ada di mana-mana dan kapan saja, dan menjadi intensif kalau manusia beriman mengalaminya. Sebelumnya diyakini bahwa tempat Allah kudus dan dilarang dimasuki manusia. Dipahami bahwa ada garis pemisah antara yang ilahi dan yang manusiawi. Pengalaman Yakub ini melukiskan keyakinan baru (transisi) bahwa manusia tinggal di tempat Allah. ${ }^{3}$

Kekhasan satu tempat muncul kalau suatu peristiwa penting terjadi di tempat itu. Kekhasan waktu dikenang karena suatu peristiwa bersejarah ada di saat tersebut. Orang beriman yang bergerak dalam tempat dan dalam waktu mengalami kehadiran Allah di mana dia berada dan pada zamannya. Kisah nyata inkarnasi Yesus terjadi di Betlehem di tanah Israel, tetapi kejadian iman hebat itu juga menyatakan bahwa seluruh bumi merupakan tempat inkarnasi dan tempat Dia

2 John J. Scullion (Translator), Genesis 12-36, Mineapolis, Augsburg Publishing House 1985, hlm. 456.

${ }^{3}$ John J. Scullion, Genesis 12-36..., hlm. 457. 
berada, sehingga orang beriman di mana dan kapan saja berada bisa mengalami bahwa Allah hadir di tempat dan di saat dia berada.

Manusia yang terbatas di konteks waktu dan tempatnya mampu mengalami kehadiran Yang Ilahi dengan pengalaman dan pengungkapan iman dan bahasanya. Demikian halnya dengan paham dan pengalaman berada di bumi bisa berbeda karena dibentuk dan dipengaruhi warisan pengalaman, tradisi, dan konteks secara menyeluruh.

Kearifan masyarakat berkembang berjalan bersama tradisi yang dimiliki. Sebagaimana Yakub mengalami dan mengungkapkan kehadiran Allah, di tempat dan di waktunya, kita juga mengalami dan mengungkapkan, "Di sini ada Allah...." Identitas orang beriman ditentukan bukan hanya oleh orang yang dikenal, dan oleh Allah yang dicintai, tetapi juga oleh lingkungan alam: oleh jurang, oleh pohon dan air yang memelihara jiwa manusia. Keadaan tempat sangat menentukan identitas orang beriman. Manusia menemukan diri ketika mengenal tempatnya dan ketika kembali ke lokasinya, dan kalau membiarkan diri dibentuk oleh lingkungan yang membuat manusia makin manusiawi. ${ }^{4}$

Alasdair MacIntyre mengajak manusia zaman ini untuk menggali butir keutamaan. Dikatakannya, "Kehidupan seseorang tidak pernah sendirian. 'Cerita saya selalu tertanam dalam cerita komunitaskomunitas yang darinya saya memperoleh identitas saya'. Saya hanyalah diri saya sebagai anggota keluarga saya, desa saya atau komunitas, suku saya, daerah saya, bangsa saya, umat agama saya." 5 Ditambahkannya, keutamaan perlu dipelihara. Keutamaan membiasakan orang memiliki kesadaran memadai tentang tradisitradisi di mana seseorang menjadi partisipan dan menghadapinya. ${ }^{6}$

Pemahaman dan pengenalan orang akan diri, alam dan Sang Pencipta bertumbuh bersama warisan tradisi yang dimiliki dan juga bersama gagasan pengetahuan yang diperoleh dalam perjalanan. Asia memiliki kekayaan tradisi, dan juga mengalami perjuangan khas untuk mempertahankan eksistensi lokalitasnya dari penjajahan oleh bangsa

\footnotetext{
${ }^{4}$ Jay B. McDaniel, With Roots and Wings, Christianity in an Age of Ecology and Dialogue, New York, Orbis Books 1995, hlm. 97.

${ }^{5}$ Pendapat Alasdair MacIntyre dalam Franz Magnis-Suseno, 12 Tokoh Etika Abad ke-20, Yogyakarta, Kanisius 2000, hlm. 205.

${ }^{6}$ Pendapat Alasdair MacIntyre dalam Franz Magnis-Suseno, 12 Tokoh Etika..., hlm. 206.
} 
asing, juga tekanan politis internal dan tekanan mayoritas agama dan kelompok tertentu.

Satu sifat budaya dan tradisi religius di Asia adalah tradisi kosmis.7 Indonesia sebagai bagian Asia memiliki beberapa tradisi religius kosmis. Salah satu budaya yang memiliki tradisi religus kosmis adalah budaya Batak-Toba ${ }^{8}$. Budaya Batak-Toba memiliki kisah penciptaan bumi dan manusia.

\section{Kisah Bumi Kita}

Orang Batak-Toba yang beriman Kristen selain memiliki tradisi Kristen (kental dengan budaya Israel di Timur Tengah dan Latin di Eropa), juga memiliki tradisi religi lokal Batak-Toba yang tumbuh di Gunung Pusuk Buhit - Samosir dan kemudian menyebar di sekitarnya. Tradisi religi Batak-Toba ini bertahan dan berpengaruh sampai sekarang karena dihayati dengan merayakan beberapa peristiwa penting sesuai tata budaya (praktek adat-istiadat). Menarik bahwa orang Batak-Toba memiliki Kisah Penciptaan bumi bersama isinya. Nilai ilahi dan manusiawi yang melekat di dalam Kisah Penciptaan dan nilai budaya diwarisi dan diwariskan oleh orang Batak di daerah Batak dan juga di perantauan.

Beberapa warisan nilai berharga dalam Kisah Penciptaan bumi menurut budaya Batak.

a. Allah Pencipta Maha besar (Mulajadi Nabolon) menciptakan bumi dan isinya. Ide tentang ini dirumuskan dengan "Dia sanggup menjadikan apa saja yang ingin dibuat-Nya hanya dengan perkataan saja." ${ }^{9}$ Kisah ini terjadi di Dolok Pusuk Buhit (Gunung Pusuk Buhit) pinggir Danau Toba dekat Pulau Samosir. Allah menciptakan segala sesuatu dari ketiadaan. Sangat jelas bahwa Pencipta berbeda dengan ciptaan-Nya. Allah juga menciptakan hewan dan tumbuhan

7 Ada beberapa Teologi lahir di Asia, misalnya, Teologi Minjung di Korea, Teologi Kerbau di Muangthai, Inkulturasi di Srilangka, dll.

${ }^{8}$ Budaya Batak-Toba dimiliki dan dihidupi suku Batak-Toba baik yang tinggal di daerah Batak maupun yang di perantaun. Ada beberapa teori mengenai asal usul suku ini, tetapi keyakinan lebih condong bahwa suku ini merupakan proto melayu yang memiliki kisah penciptaan bumi. Kisah penciptaan itu terjadi di Gunung Pusuk Buhit dan sekitarnya.

9 Anicetus B. Sinaga, Allah Tinggi Batak-Toba, Yogyakarta, PT Kanisius 2014..., hlm. 236. 
dan benda-benda lain di bumi. Mulajadi Nabolon mencipta bumi secara berproses dan melibatkan pembantu-Nya Sideang Parujar. Bumi yang dicipta merupakan tempat sakral, subur, dan membahagiakan. ${ }^{10}$

b. Ada dua penguasa di benua tengah ${ }^{11}$, yaitu Sideang Parujar yang menopang eksistensi benua tengah; dan Naga Padoha yang menolak dan melawan perwujudan penciptaan Benua Tengah. ${ }^{12}$

c. Sideang Parujar melahirkan manusia perdana di bumi (Benua tengah). Keturunan Sideang Parujar dihukum karena keras kepala. Sideang Parujar lepas dari hukuman dan kembali ke Benua Atas dan bertenun sepuasnya di bulan. ${ }^{13}$

d. Allah mencipta segala sesuatu. Walaupun diyakini bahwa Allah mencipta segala sesuatu, agama tradisional Batak Toba tidak menjelaskan bahwa Allah juga mencipta Naga Padoha. ${ }^{14}$

e. Perayaan Tahun Baru memiliki makna. Dalam perayaan ini diadakan reaktualisasi tindak penciptaan ulang Benua Tengah menjadi asli dan murni (sakral). Diyakini bahwa pada awal-mula terdapat hubungan harmonis dan sempurna antara manusia dengan Allah dan bersama dengan alam. Dalam Perayaan Tahun Baru, dirayakan penciptaan ulang; manusia dengan bantuan Allah. Kegiatan-kegiatan keagamaan Batak bermuatan pemulihan keakraban dengan Allah. Daya iblis dihancurkan lalu Benua Tengah disucikan dan ditata ulang agar damai dan bahagia. Allah Tinggi dimohon turun dan melaksanakan kembali kegiatan penciptaan baru. Dalam perayaan tersebut, kurban kerbau, lambang Benua Tengah dan unsur-unsurnya dibunuh, dan dengan demikian Benua Tengah dicipta ulang dengan penghayatan optimis. ${ }^{15}$ dan Benua Bawah.

${ }^{10}$ Anicetus B. Sinaga, Allah Tinggi..., hlm. 47, 54, 61, 92, 93, 94.

${ }^{11}$ Dalam kisah penciptaan ada tiga benua: Benua Atas, Benua Tengah,

${ }^{12}$ Anicetus B. Sinaga, Allah Tinggi..., hlm. 100.

${ }^{13}$ Anicetus B. Sinaga, Allah Tinggi..., hlm. 96.

${ }^{14}$ Anicetus B. Sinaga, Allah Tinggi..., hlm. 102.

${ }^{15}$ Anicetus B. Sinaga, Allah Tinggi..., hlm. 122, 176, 177. 
f. Digunakan janur sebagai lambang untuk menandakan daya ilahi dalam kesuburan dan keindahan alam. Kesuburan pertanian dan ternak dilihat sejajar dengan kesuburan manusia. Sumber sejati kesuburan dan penyelengaranya adalah Mulajadi Nabolon. ${ }^{16}$

g. Sistem waktu yang dirayakan dalam ritus Batak Toba merupakan pengulangan ke awal. Keabadian dihayati dengan pengulangan ke awal, bukan dalam waktu linier eskatologis. Perayaan Tahun Baru adalah pengembalian waktu ke pada permulaan, bukan pengarahan ke masa depan. ${ }^{17}$

\section{Pariwisata}

Daerah tempat lahir dan bertumbuh budaya dan religi Batak sangat indah. Tanah Batak yang berada di bentangan Bukit Barisan sangat menarik karena dihiasi oleh rangkaian bukit-bukit dan beberapa tanjung berlekuk, juga disegarkan oleh air dan keindahan Danau Toba, serta diperkaya Pulau Samosir. Keindahan alami yang bisa dipandang dengan mata kepala, makin lengkap dengan ritus religi yang bisa dilihat dengan mata hati dan mata rohani. Keindahan alam dan muatan religi daerah dan budaya ini menjadi daya pikat untuk tujuan wisata.

Dengan bervariasi promosi, termasuk salah satu cara dengan menyebarkan stiker "wecome to Samosir!" para turis diundang dan mereka yang datang menjadi pelaku dinamika budaya. Kegiatan pariwisata sangat berhubungan erat dengan aktivitas bisnis yang berusaha mendatangkan sebanyak mungkin orang tanpa seleksi apakah dia menghormati budaya atau tidak. Selain itu pebisnis pariwisata berusaha mendatangkan sebanyak mungkin untung, sehingga kekayaan dan nilai budaya yang seharusnya dipromosikan, justeru bisa kurang mendapat perhatian. Kalau tidak hati-hati, kekayaan "misteri" yang sudah disebut di atas, yang dimiliki oleh daerah Batak di daerah sekitar Danau Toba, bisa terkikis sehingga kehilangan unsur fascinosum dan tremendum. Kekhasan situs religius budaya yang mengandalkan "misteri", bisa tergusur. Bisa terjadi "tondi" tanah Batak tidak berdaya dan tidak dialami oleh orang Batak sendiri dan orang lain yang datang ke daerah sekitar Danau Toba. Jelas kekayaan religius tidak bertetangan

${ }^{16}$ Anicetus B. Sinaga, Allah Tinggi..., hlm. 184, 222, 224, 232.

${ }^{17}$ Anicetus B. Sinaga, Allah Tinggi..., hlm. 235. 
dengan kemajuan ekonomi, tetapi hendaknya ekonomi/uang yang diperoleh justru menopang kekayaan tradisi religi, bukan sebaliknya menggadaikan nilai-nilai religi.

"Bisnis pariwisata cenderung mengakibatan pemanfaatan wilayah, pantai atau sumber daya air perairan, tanpa kendali." 18 Makin dirasakan bahwa pemilikan tanah komunal di wilayah pantai mulai terancam. Tanah adat dan tanah ulayat dijual sehingga muncul konflik keluarga dan klaim pemilikan tanah. ${ }^{19}$ Pemilikan tanah komunal menjadi privatisasi. Pengembangan bisnis pariwisata cenderung mengabaikan keterlibatan masyarakat setempat karna taraf kemampuan mereka kurang memenuhi persyaratan khusunya di bidang pengalaman. Perlu juga diwaspadai agar bisnis turis tidak membonceng turis seksual karena hal itu bisa merontokkan tata nilai relasi pria dan wanita, tata relasi keluarga yang sudah dibangun dalam budaya setempat.

Badan Pelaksanaan Otorita Danau Toba (BPODT) yang diharapkan bisa meningkatkan pengelolaan kekayaan alam (ekowisata) yang otomatis bisa meningkatkan kesejahteraan masyarakat setempat, serta pengembangan dengan menjaga kearifan lokal dan tradisi warisan budaya setempat, tetap dicermati. Karena informasi tidak lengkap dimiliki oleh masyarakat, di samping kemampuan masyarakat juga terbatas untuk memahaminya, isu BPODT ini sangat mempengaruhi mentalitas masyarakat. Sebagian masyarakat optimis akan muncul kemajuan secara integral, tetapi sebagian juga pesimis dan cemas bahwa mereka akan menjadi korban arus kemajuan yang dikontrol oleh pelaku investasi.

Perlu waspada karena pengelolaan pariwisata dengan ekonomi pengembang bisa menjebak dan tidak membuat perencanaan dan tidak membuat perhitungan dampak lingkungan secara jujur. Pengelolaan pariwisata "liar" pasti mengakibatkan lingkungan tercemar, sumber daya alam rusak karena penggunaannya melebihi daya dukung lingkungan. Selain itu, nilai budaya dan situs budaya lokal bisa juga rusak dan hilang. ${ }^{20}$ Ekowisata hendaknya menyemangati pengunjung

18 Markus Manurung (ed.), Membangun Pariwisata yang Bermartabat dan Berkelanjutan di Kawasan Danau Toba, Medan, Bina Media Perintis 2016, hlm. 27.

19 Bernadeta Harini Tri Prasasti, Lingkungan Hidup, Jakarta, Dokpen KWI 2014, hlm. 99, 154; Markus Manurung (ed), Membangun pariwisata..., hlm. 73.

${ }^{20}$ Markus Manurung (ed.), Membangun Pariwisata..., hlm. 43; Bernadeta Harini Tri Prasasti, Lingkungan Hidup..., hlm 94. 
untuk menghormati nilai budaya serta merayakannya sehingga berpengaruh positif bagi mereka. "The spirits and ancestors were not simply present, they were participans in the ceremony, active members of the life commuunity. Without them, the ceremony would have been incomplete."21 Spiritualitas dan kekayaan rohani bukan untuk diperjualbelikan. Orang berbudaya lain (dalam hal ini bukan berbudaya Batak) boleh belajar dari budaya tertentu (budaya Batak-Toba) dan orang berbudaya Batak-Toba boleh belajar dari orang berbudaya lain. ${ }^{22}$

Pariwisata berkelanjutan harus menjaga kelestarian alam dan keanekaragaman hayati, terlebih menghormati nilai dan tradisi kebudayaan masyarakat. Usaha pariwisata harus bermanfaat bagi masyarakat lokal serta melibatkan mereka untuk meningkatkan keadaan sosial ekonomi. Orang Kristen dan secara khusus mereka yang terlibat dalam usaha pariwisata ikut berpartisipasi mempromosikan kelestarian lingkungan hidup, sehingga masyarakat mengalami dan mengungkapkan bahwa Allah hadir di sini bersama ciptaan-Nya.

"Perlulah mendorong prakarsa-prakarsa untuk menghormati dampak lingkungan dan menjaga prioritas masyarakat lokal, bahkan bila itu harus membatasi kegiatan pariwisata. Segala upaya yang ditujukan untuk menjadikan kaum kristiani bertanggung jawab terhadap gaya hidup ugahari dengan solidaritas dalam perjalanan mereka ke negara-negara berkembang dan sia-sia jika penyelenggaraan tur dan yang memajukannya tidak dibimbing oleh kepekaan yang wajar." 23

Paus Yohanes Paulus II mengajak kaum kristiani agar membuat pariwisata, "Menjadi peluang lain untuk memandang Allah dan bertemu dengan Pencipta serta Bapa semua orang. Dengan demikian mereka diteguhkan dalam pengabdiannya bagi keadilan dan perdamaian dan dalam kesetiaan kepada-Nya yang berjanji menciptakan langit baru dan bumi baru." 24 Pedoman Pastoral Pariwisata yang diterbitkan Dewan Kepausan menunjukkan bahwa "Manusia tak

${ }^{21}$ Bernadeta Harini Tri Prasasti, Lingkungan Hidup..., hlm. 96; Jay B. McDaniel, With Roots and Wings..., hlm. 200.

22 Jay B. McDaniel, With Roots and Wings..., hlm. 193.

${ }^{23}$ Bernadeta Harini Tri Prasasti, Lingkungan Hidup..., hlm. 83-84.

${ }^{24}$ Bernadeta Harini Tri Prasasti, Lingkungan Hidup..., hlm. 96. 
pernah boleh lupa bahwa seluruh ciptaan adalah anugerah yang senantiasa berbicara tentang kebaikan Allah dan Pencipta." 25

\section{Beriman yang Membudaya}

Menarik untuk mendalami pertanyaan di sampul belakang buku Dr. Anicetus B. Sinaga, "Apakah seorang Batak yang iklas menolak pengalaman agamanya sendiri atau ia harus memperdalamnya sambil menganut kekristenan?"26 Dari ungkapan singkat di atas, jelas bahwa orang Batak-Toba mengalami kehadiran dan kebaikan Allah secara khas di tanah Batak-Toba. Dengan menghidupi keyakinan religius yang bermuatan nilai-nilai dan kebiasaan baik termasuk menghargai bumi dan isinya, orang Batak-Toba bisa mengalami dan mengungkapkan bahwa Allah hadir "di sini" di tanah Batak. Allah juga berkarya di tanah dan di budaya Batak. "Equally important, however, they invite us to recognize that our spiritual identities are part formed by the very geographies and life communities in which we are situated." 27 Orang Batak-Toba dengan kekayaan kisah penciptaan dan kekayaan alam sekitar dipanggil untuk melestarikan ciptaan dan kekayaan unsur hayati dan non hayati yang ada di bumi ini. Dengan menghayati panggilan ini Sang Pencipta tetap berkarya dan dialami nyata ada di sini.

Di sisi lain, iman kristen yang memuat ajaran Kristus nyata bertumbuh subur di tanah Batak. "Menjadi 'Kristus yang lain' tidak berarti menjadi seorang laki-laki Yahudi tetapi menjadi diri kita sendiri sampai pada kebenaran identitas kita dan dalam pengenalan diri yang benar." 28 Orang Batak-Toba yang beriman Kristen menghidupi iman kristen transformatif di konteks tradisi dan religi Batak-Toba.

Iman Kristen bertumbuh subur dalam hidup umat yang berbudaya Batak. Dengan menggali nilai budaya Batak dan menghidupinya seorang Batak yang Kristen mengalami Allah hadir di sini. Dengan menghidupi nilai budaya khususnya yang berhubungan dengan penghargaan dan perawatan bumi dan isinya, orang Batak-Toba yang tidak Kristen juga mengalami bahwa Allah hadir di sini. Allah

25 Pedoman Pastoral Pariwisata dalam Bernadeta Harini Tri Prasasti, Lingkungan Hidup..., hlm. 97.

${ }^{26}$ Anicetus B. Sinaga, Allah Tinggi... sampul belakang.

${ }^{27}$ Jay B. McDaniel, With Roots and Wings..., hlm. 196.

${ }^{28}$ Ilia Delio, Doa Fransiskan, Medan, Bina Media Perintis 2018, hlm. 185. 
yang Maha Rahim mengandung semua ciptaan sehingga akar nilai yang berbeda karena manusia berada di multi kultur bisa saling berelasi dan saling menguatkan. Keberagaman ciptaan dan nilai kultural mengandung "kehadiran" Allah yang mengandung segalanya.

Kehadiran Allah Maha Besar bisa dialami dan diungkapkan oleh manusia di kontes budayanya. Orang Batak-Toba menyebut Pencipta dan Penyelenggara cipataan Mula Jadi Nabolon. Dengan Iman transformatif kontekstual orang Kristen meyakini bahwa Pencipta bumi dan semua isinya adalah Allah yang Maha Esa.

\section{Penutup}

Refleksi ekologis kontekstual menyegarkan penghayatan iman bahwa Allah Pencipta hadir dan berkarya di tempat dan waktu serta di budaya yang hidup di tempat tertentu. Di tanah Batak-Toba dan di budaya yang hidup di tempat ini kehadiran dan karya Pencipta tampak indah. Pesona alami dan ilahi mendukung pengembangan ekonomi pariwisata. Ajakan Paus Yohanes Paulus II sangat baik menjiwai kegiatan pengembangan ekonomi pariwisata. Paus ini mengajak agar kegiatan pariwisata memampukan manusia memandang Allah dan bertemu dengan Pencipta dan Bapa semua orang. Kegiatan pariwisata dan aktivitas yang mengandalkan kekayaan dan keindahan alami ciptaan seharusnya mendukung masyarakat setempat untuk mengalami dan mengungkapkan bahwa Allah hadir sini bersama ciptaan-Nya. 
Largus Nadeak, Allah Pencipta hadir Di Sini Bersama Ciptaan-Nya

\section{DAFTAR PUSTAKA}

Delio, Ilia. Doa Fransiskan, Medan, Bina Media Perintis 2018.

Magnis-Suseno, Franz. 12 Tokoh Etika Abad ke-20, Yogyakarta, Kanisius 2000.

Manurung, Markus (ed.). Membangun Pariwisata yang Bermartabat dan Berkelanjutan di Kawasan Danau Toba, Medan, Bina Media Perintis 2016.

McDaniel, Jay B. With Roots and Wings, Christianity in an Age of Ecology and Dialogue, New York, Orbis Books 1995.

Prasasti, Bernadeta Harini Tri. Lingkungan Hidup, Jakarta, Dokpen KWI 2014.

Scullion, John J., Genesis 12-36, Mineapois, Augsburg Publishing House 1985.

Sinaga, Anicetus B. Allah Tinggi Batak-Toba, Yogyakarta, PT Kanisius 2014. 